\begin{tabular}{|l|l|}
$\begin{array}{l}\text { Postprint } \\
\text { Version }\end{array}$ & 1.0 \\
\hline Journal website & https://linkinghub.elsevier.com/retrieve/pii/S1526-0542(17)30005-2 \\
\hline Pubmed link & $\underline{\text { https://www.ncbi.nlm.nih.gov/pubmed/28283301 }}$ \\
\hline DOI & 10.1016/j.prrv.2017.01.003 \\
\hline
\end{tabular}

This is a NIVEL certified Post Print, more info at http://www.nivel.eu

\title{
Can we trust what parents tell us? A systematic review.
}

\author{
PAUL L.P. BRAND ${ }^{\mathrm{A}, \mathrm{B},{ }^{*},}$ SANDRA VAN DULMEN ${ }^{\mathrm{C}, \mathrm{D}, \mathrm{E} \text { A }}$ \\ a'Isala Women's and Children's Hospital, Zwolle, the Netherlands \\ 'UMCG Postgraduate School of Medicine, University Medical Centre and University of \\ Groningen, Groningen, the Netherlands \\ ${ }^{c}$ Dept. of Primary and Community Care, Radboud University Medical Centre, Nijmegen, the \\ Netherlands \\ ${ }^{d}$ NIVEL (Netherlands institute for health services research), Utrecht, the Netherlands \\ ${ }^{e}$ Faculty of Health Sciences, University College of Southeast Norway, Drammen, Norway
}

\begin{abstract}
SUMMARY
Taking a history is a key diagnostic instrument in paediatric consultations. Numerous issues potentially reduce the history's reliability. Therefore, paediatricians have always expressed ambivalence regarding history taking from parents, both valuing and distrusting it. In this review, we describe how parents build and present a description of their child's health issues in the conceptual framework of self-regulation theory. We performed a systematic review on the literature on the reliability of history taking. No studies examined the reliability of history taking from parents, but there is a considerable body of evidence on the issue of mutual trust in relationships between health care professionals and patients. Because trust is a dynamic relational phenomenon, taking a patient centred approach in consultations is likely to increase the patients' and parents' trust in the health care professional, and their willingness to follow the health care professional's treatment proposals. We provide evidence based recommendations on how to build and maintain trust in paediatric consultations by taking a patient centred approach in such consultations.
\end{abstract}

\section{INTRODUCTION}

Taking a history is a key diagnostic instrument in all disciplines of medicine, including paediatrics [1]. Although every paediatrician will appreciate the importance of obtaining medical information directly from the patient, history taking in young children relies mainly on the parents' representation of the child's problems. To be helpful in making a diagnosis or assessing disease status during follow-up, the history should be reliable, i.e. it should reflect the child's health issues as accurately as possible. 
The issues potentially reducing the history's reliability are numerous. It is important to realize that the interpretation and presentation of the child's problems are always affected by parents' emotions, such as anxiety, grief, or concern [2]. For example, the person(s) presenting the history may exaggerate the child's problems (e.g., to appeal to the physician to attend to the problem) or downplay them (e.g., not to overburden the physician, or to give the impression that they have control of their child's problems) [3]. Parents often think they know how the child behaves, also with respect to the child's disease and its treatment, when in fact they do not, either because the child does not want the parent to know (e.g., when the child fails to take medication thus denying the existence of the disease) or because the parent's assessment is incorrect (e.g., about how faithfully the child takes the prescribed daily medication) [4]. Parents can deny the child's problems or issues. Parents can have insufficient exposure to the child's daily life to be able to provide an accurate representation of the child's problems, e.g. when parents are divorced and children move between houses. Or parents may deliberately falsify the information as a result of their own psychiatric disease, e.g. paediatric condition falsification disorder. All of these phenomena may reduce the reliability of the medical history being obtained from the parents, and this may result in under- and over-diagnosis, unnecessary testing, and incorrect treatment.

The abundance of potential barriers threatening the reliability of history taking makes it impossible to address each of these in detail in every consultation. Practicing paediatricians therefore need simple tools to gauge the reliability of the history they obtain from patients and parents regarding their patients' medical condition. Despite the obvious importance of this issue, it has been hardly touched upon in medical journals.

In this review, we describe how parents build and present a description of their child's health issues in a conceptual framework, present results of a systematic review on the reliability of history taking, discuss these in the context of relevant other literature, and conclude with evidence based recommendations of what health care professionals can do to increase the likelihood of obtaining accurate and reliable information when taking a history.

\section{CONCEPTUAL FRAMEWORK}

A useful model to describe and understand the human response to threats such as disease is Leventhal's self-regulation theory (Box 1) [5]. This theory is built on the premise that humans adapt to threats via coping procedures that make efficient use of resources based upon valid representations of the environment. For health threats, this involves illness representations and coping procedures.

\section{[BOX 1]}

Illness representations are individuals' common-sense definition of health threats. Importantly, both the content and organization of illness representations are shaped by personal beliefs and experiences, which, in turn, are mainly determined by cultural background, personal history (e.g., the way in which health issues and threats were dealt with in the individuals' own youth), and information and experiences from peers (e.g., things parents hear from other parents in school yards, support groups, and from friends and family) [5]. 
Coping procedures represent the way in which individuals respond to health treats.

Describing the abundant research on coping is beyond the scope of this review.

Coping procedures are dependent on illness representations, which in turn may evolve based on the perceived result of the coping procedures; on the expected outcome of the procedure; and on the perceived risks and benefits of the coping procedure [5].

In self-management of chronic diseases involving the use of daily controller medication, Leventhal's self-regulation theory has been translated into a "common sense" model by Horne (Figure 1) [6]. In this model, adequate self-management of chronic disease is based on balancing the perceived need and perceived concerns of treatment. The perceived need is driven by illness cognitions (the illness representations in Leventhal's model). The perceived concerns may be a specific fear of side effects or represent a negative orientation to medicines in general. Importantly, both the illness cognitions and the medication beliefs are more strongly determined by the individual's personal background, experiences and information network than by information and education provided by health care professionals. Thus, although the illness perceptions and concerns about medication expressed by the -parents of a child with a chronic serious respiratory condition may strike the physician as irrational and unjustified, they do make common sense to the parents, and they drive self-management behaviour [3,7]. Because they are usually not disclosed spontaneously, it is important that the health care professional actively explores these perceptions, and expresses understanding and respect for their presence and importance to the parents [2,7].

\section{METHODS OF LITERATURE SEARCH}

We designed a sensitive literature search strategy to identify scientific articles dealing with the reliability of information presented by parents in a medical history of their child's condition. We operationalized the search strategy by using a combination of search terms targeted at medical communication, trust, and the parents' perspective (for detailed information about the search strategy, see Appendix 1). We searched PubMed, Embase, and Psycinfo until September 1, 2016. Titles and abstracts of retrieved papers were screened for relevance by the first author, and full texts of relevant papers were read and discussed by both authors. Differences about relevance, content, and interpretation were resolved by consensus.

\section{RESULTS OF LITERATURE SEARCH}

The search strategy (Appendix 1) yielded 150 articles, 15 of which were considered potentially relevant after reading title and abstract. No article dealt directly with reliability of history taking from parents in consultations about children's health. Nine of the 15 retrieved articles were considered relevant to our research question and were included in the review (Table 1). Because of considerable clinical and statistical heterogeneity, we refrained from quantitative data extraction or metaanalysis. Results of the included studies are therefore only presented qualitatively, and in chronological order of publication. 


\section{[TABLE 1]}

Levinson et al described the development of a questionnaire to capture "frustrating" consultations by primary care practitioners. Lack of trust was one of the seven sources of frustration physicians experience in their consultations, and could be the result of perceived lack of trust between physician and patient, the patient being unwilling to accept the diagnosis, patient and physician not agreeing on the consultation's goal, and the physician having the impression that the patient did not believe him [8].

Rogers published an essay on the moral obligation of doctors to trust their patients. He argued not only that trust is needed to support the exercise of patient autonomy, but also that this will enrich the understanding of patients' interests. According to Rogers, "the burdens of misplaced trust fall more heavily upon patients than doctors". The following barriers of trust were described: medicine's strive for objectivity ("patients cannot be trusted to know the relevant details from the insignificant"), the social context of medicine (time constraints, the possibility of violence and complaints from patients, patient is a stranger to the physician), and the manifestations of dissatisfaction and weariness in the physician [9].

In their article arguing that a history should be built rather than taken, Haidet and Paterniti described that patients and physicians each have their own unique perspective on the illness experience, and that this affects the way in which they exchange information relevant to it. They reviewed literature showing that patients who are able to fully shape their perspective achieve better outcomes [10].

In a historical overview on how doctors write about the conduct of encounters with parents on children's illnesses, Gillis reported that throughout the published history of medicine doctors have always expressed ambivalence regarding taking a history from parents, both valuing and distrusting it [11].

In their cross-sectional study of 214 patients visiting 28 primary care practitioners, Street and co-workers described how perceived personal similarity in beliefs and values, and the physician's patient-centred communication style, predicted the patient's trust, satisfaction, and intent to adhere [12].

Ammentorp and Kofoed described how Danish patients felt that their paediatrician tried better to understand how the patient experienced their problem after completion of a communication course [13].

Thom et al described the development and validation of an instrument to assess the physician's trust in the patient, based on 61 primary care practitioners' experiences with 168 hiv positive adults [14]. Their 12-item "Trust in the patient scale" has not been validated in other settings.

In the only published systematic review on trust in the physician-patient relationship, Brennan and co-workers found that almost all studies in this area dealt with patients' trust in their doctors. None of the few studies examining physicians' trust in patients dealt with children's consultations [15].

Finally, Riva et al. analyzed interviews with 100 adults in primary care in Italy, and found that trust was driven much more by simple communication signals from doctors ("honest signals") than by content-dependent features of the consultation [16]. 


\section{RELIABILITY OF HISTORY TAKING}

Although paediatricians have expressed ambivalence regarding history taking from parents for over a century, both valuing and distrusting it [11], our systematic review did not find any study investigating the reliability of such history taking from parents in paediatric health care. This may be due to the complexities involved in such studies. Rigorous studies on the reliability of diagnostic instruments require a reference test (gold standard) [17]. However, the symptoms recorded in a history are by definition the patient's subjective experiences for which no objective reference standard is available. For children's health care problems, the history usually involves the parents' representation of the signs and symptoms they hear from, or observe in, their children, adding another layer of subjective interpretation. The patient's (or parents') interpretation of symptoms and signs is inevitably tainted by emotions and psychological defence mechanisms [18]. This flaw of parental history taking has been recognized as both fundamental and inevitable since paediatrics became a distinct medical specialty [11]. It also applies to a large degree to history taking from adult patients. Although a few studies have examined the reliability of specific history data in adults $[19,20]$, we have not found any studies on the overall reliability of history taking in adults either. In addition to the absence of a reliable reference standard for information obtained through taking a history, the execution of studies on the reliability of history taking also inevitably touches on the issue of trust in the paediatrician-parent-child relationship. If parents are informed that a study is being undertaken to evaluate the reliability of the history they provide on their child's health issues during a clinical interview, this may influence both their sense of being trusted by the paediatrician and their trust in the paediatrician.

A considerable body of evidence exists on the issue of trust between patients and health care professionals. In such relationships, trust can be characterized as an attitude relying with confidence on someone [21]. Almost all studies in this area deal with the patient's trust in the physician or other health care provider [15,22]. A recent qualitative study among emergency physicians showed that many of them made judgements on the reliability of their patients' accounts from the very beginning of the encounter, and that they used a variety of techniques to cross-check the reliability and consistency of the history data provided by the patient [23]. They argued that it is important to find out how these credibility judgements affect medical decision making. Although we found no similar studies in paediatricians, it is likely that they also make such credibility judgements in clinical encounters. Trust in relationships between patients and health care providers is a dynamic process, not a fixed characteristic [21]. It is influenced by the degree of power imbalance in the relationship (vulnerability and dependency of the truster), and is determined more strongly by relational and communication aspects than by the medical content of the consultation $[12,16,21,22]$. Because of the importance of trust in the clinical encounter [9,24], it is understandable that clinician-researchers shy away from undertaking history reliability studies potentially undermining the patient's trust in the doctor. Therefore, scientific, ethical and practical reasons hinder the execution of studies on the reliability of history taking in paediatrics.

\section{DOCTOR'S OR PATIENT'S PERSPECTIVE?}

With the inevitable ambiguity of medical history taking in mind, paediatricians have always tended to value "objective" data from their own observation, physical 
examination, or laboratory or imaging investigations more than having to rely on the "subjective" data from the history [11]. Consequently, "taking a history" is being viewed as a technical skill, involving the use of a specific heuristic to guide the interview, organized along a disease-oriented paradigm [10]. It is primarily aimed at collecting relevant biomedical information supporting clinical reasoning by the physician [25]. Traditionally, history taking thus primarily serves the doctor's, not the patient's, perspective, reflecting the long domination of the paternalistic model in medicine [26].

During the last decades of the 20th century, different models of the doctor-patient relationship in medical encounters began to emerge in which the patient is more active and the patient's perspective on his or her medical problems and their treatment plays a more prominent role [26]. The model based on collaboration between physician and patient, aiming at achieving a shared decision, is gaining recognition and attention in the medical literature, for reasons to be discussed below $[27,28]$.

\section{IMPORTANCE OF THE PATIENT'S PERSPECTIVE AND SHARED DECISION MAKING}

The evidence supporting the importance of taking the patient's perspective into account in medical consultations is considerable.

Firstly, patients prefer humane and personalized care, which is person-centred rather than focusing on disease [29,30]. Although some physicians maintain that circumstances and patient characteristics may require a paternalistic approach in many cases [31], there is increasing support for the proposition that physicians have the ethical obligation to involve patients in medical decisions [32-34], and that patient's views and preferences need to be taken into account in these decisions [3537].

Secondly, patients prefer a physician with whom they can collaborate [38-42]. Although many patients trust their physician to act in their best interest [31], most prefer that the physician involves them and their perspectives in medical decisions $[33,43]$. Similarly, most physicians support the concept of collaborative deliberation towards a shared decision, but the level of support varies by clinical scenario, treatment decision and patient characteristics [44]. Although the support for collaborative models of the physician-patient relationship appears to be strong, therefore, physicians struggle with its application. The most commonly reported barriers physicians report in their application of shared decision making are time constraints, patient characteristics, and the clinical situation [45,46]. A more subtle barrier in exploring the patient's perspective and the application of shared decision making may be the scientific culture of medicine with its traditional focus on unravelling and understanding disease mechanisms [47], and its reliance on evidence based guidelines [48]. Clinicians tend to follow the recommendations from these guidelines, irrespective of the preferences and context of the patient [49]. In addition, they use at least two subtle strategies to steer their patients towards their preferred treatment option by "cherry picking" the information supporting their preferred option [50], and by using subtle deprecating expressions about the patient's preferences [51]. Most communication in paediatric consultations is "instrumental", i.e. aimed at the doctor's agenda of clinical reasoning [52]. In a study of audiotaped consultations of 333 children with asthma and their parents in 5 paediatric practices 
in North Carolina, USA, input on the management plan by parents and children was obtained in $<10 \%$ of visits [53].

Thirdly, and perhaps most importantly, taking the patient's perspective into account in shared decision making improves outcomes for patients. Patient satisfaction with the consultation increases with increased application of shared decision making skills by physicians [54]. Health outcomes also improve when the patient's perspective is taken into account [10,55], and when shared decision making is applied [56]. This is related to improved adherence to the physician's recommendations [12,57-60]. Studies in childhood asthma have shown that the patient's and parents' medication beliefs are the main determinant of adherence to daily controller therapy with inhaled corticosteroids $[61,62]$, that high adherence can be achieved through patient-centred care with concordance on treatment goals and strategies $[63,64]$, and that good adherence is strongly associated with achieving and maintaining good asthma control [65].

\section{TOWARDS EFFECTIVE CONSULTATIONS BASED ON MUTUAL TRUST}

Our systematic review shows that there is no valid scientific evidence on the reliability of history data provided by parents in paediatric consultations, and that it is highly unlikely that such studies will ever be undertaken due to practical, ethical, and scientific barriers. Because of the importance of history data in clinical reasoning, and in the light of the moral and ethical principles of our profession, we have to make do with what parents tell us. Paediatricians need to trust the information provided in history taking until we are proven wrong, for example in the context of paediatric condition falsification disorder.

So what can paediatricians do to increase the likelihood that the information they obtain in history taking from parents is accurate, trustworthy and useful? The literature discussed above indicates that taking a patient centred approach and applying shared decision making improves parents' satisfaction with the consultation, their adherence to the proposed treatment plan, and the health outcomes of their child. This strongly suggests that the information that the clinician is using in these consultations is useful and valid, and a considerable proportion of this information comes from history taking. It is highly likely, therefore, that taking a patient centred approach in medical consultations helps to improve the accuracy and reliability of history data.

Although few doctors have been trained in patient centred communication skills $[66,67]$, a number of reviews provide similar recommendations on what paediatricians can do to enhance patient centred care in consultations $[7,63,68,69]$. These are summarised in Table 2. Because trust is strongly (inter)relational by nature, paediatricians can improve mutual trust by fostering a respectful and constructive relationship with parents $[7,68,70]$. This begins at the very start of the consultation: the first few minutes of a consultation can have significant effects on the outcome of the visit, including how decisions are made [69]. Eliciting the patient's perspective includes active exploration of illness and medication beliefs, because of their importance in determining adherence [71], and a discussion of cultural and religious influences which may have an impact on treatment choices. To explore these perceptions, the same technique of "curious pursuit" can be used that doctors apply when probing the patient for medical information in the history [7]. Parents usually appreciate a paediatrician who shows a genuine interest both in the 
medical condition of the patient, and in the patient and family as persons. Fostering the relationship continues throughout the consultation. Actively involving patients in options, and weighing their pros and cons, helps to co-create the option which best serves the patient's interest, both medically and personally. After providing the opportunity to ask further questions, explicit agreement on the co-created plan between paediatrician and parents helps to increase the likelihood of the patient and parents adhering to the plan $[64,69]$.

\section{[TABLE 2]}

\section{CONCLUSIONS}

Can we trust what parents tell us during history taking? We don't know and probably never will, but we have to. Trust is a dynamic and bilateral phenomenon, so the best way to increase trust in the patient is to foster and nourish the patient's trust in us. This can be achieved by applying principles of patient centred care.

\section{EDUCATIONAL AIMS}

The reader will be able to appreciate that

- Paediatricians express ambivalence of both having to value and to distrust the history provided by parents

- There is absence of evidence on the reliability of history data provided by parents

- There is a considerable body of evidence indicating that a patient centred approach in consultations increases the reliability of history data provided by parents

- Practical guidelines are available on how to provide patient centred care in medical consultations

\section{DIRECTIONS FOR FUTURE RESEARCH}

- Investigate to what extent parents downplay or exaggerate their children's medical complaints and to investigate determinants of such behaviour

- Impact of credibility judgements made by paediatricians about the parents of their patients on medical decision making by paediatricians

- Delineate the key components of patient centred care as viewed by parents of children with chronic conditions

- Effect of patient centred communication style on reliability of history data provided by parents

\section{ACKNOWLEDGEMENTS}

The authors wish to express their gratitude to Mirell Papenhuizen, clinical librarian at Isala Hospital, Zwolle, the Netherlands, for her invaluable help in conducting the systematic literature search.

\section{APPENDIX A. SUPPLEMENTARY DATA}

The following is Supplementary data to this article: 
Brand, P.L.P., Dulmen, S. van. Can we trust what parents tell us? A systematic review.

Paediatric Respiratory Reviews: 2017, 24, 65-71

\section{REFERENCES}

[1] M.C. Peterson, J.H. Holbrook, D. Von Hales, N.L. Smith, L.V. StakerContributions of the history, physical examination, and laboratory investigation in making medical diagnoses West J. Med., 156 (2) (1992), pp. 163-165

[2] P. Maguire, C. PitceathlyKey communication skills and how to acquire them BMJ, 325 (7366) (2002), pp. 697-700

[3] J. Lawton, N. Waugh, K. Noyes, K. Barnard, J. Harden, L. Bath, et al.Improving communication and recall of information in paediatric diabetes consultations: a qualitative study of parents' experiences and views BMC Pediatr., 15 (2015), p. 67

[4] T. Klok, S. Lubbers, A.A. Kaptein, P.L. BrandEvery parent tells a story: why nonadherence may persist in children receiving guideline-based comprehensive asthma care J. Asthma, 51 (1) (2014), pp. 106-112

[5] H. Leventhal, E.A. Leventhal, R.J. ContradaSelf-regulation, health, and behavior: a perceptual-cognitive approach Psychol. Health, 13 (1998), pp. 717-733

[6] R. Horne, S.C. Chapman, R. Parham, N. Freemantle, A. Forbes, V. CooperUnderstanding patients' adherence-related beliefs about medicines prescribed for long-term conditions: a meta-analytic review of the Necessity-Concerns Framework PLoS One, 8 (12) (2013), p. e80633

[7] L.B. Mauksch, D.C. Dugdale, S. Dodson, R. EpsteinRelationship, communication, and efficiency in the medical encounter: creating a clinical model from a literature review Arch. Intern. Med., 168 (13) (2008), pp. 1387-1395

[8] W. Levinson, W.B. Stiles, T.S. Inui, R. EnglePhysician frustration in communicating with patients Med Care, 31 (4) (1993), pp. 285-295

[9] W.A. Rogersls there a moral duty for doctors to trust patients? J Med Ethics, 28 (2) (2002), pp. 77-80

[10] P. Haidet, D.A. Paterniti“"Building" a history rather than "taking" one: a perspective on information sharing during the medical interview Arch Intern Med, 163 (10) (2003), pp. 1134-1140

[11] J. GillisTaking a medical history in childhood illness: representations of parents in pediatric texts since 1850 Bull Hist Med, 79 (3) (2005), pp. 393-429

[12] R.L. Street Jr., K.J. O'Malley, L.A. Cooper, P. HaidetUnderstanding concordance in patient-physician relationships: personal and ethnic dimensions of shared identity Ann Fam Med, 6 (3) (2008), pp. 198-205

[13] J. Ammentorp, P.E. KofoedThe long-term impact of a communication course for doctors and nurses: the parents' perspective Commun Med, 7 (1) (2010), pp. 3-10

[14] D.H. Thom, S.T. Wong, D. Guzman, A. Wu, J. Penko, C. Miaskowski, et al.Physician trust in the patient: development and validation of a new measure Ann Fam Med, 9 (2) (2011), pp. 148-154

[15] N. Brennan, R. Barnes, M. Calnan, O. Corrigan, P. Dieppe, V. EntwistleTrust in the health-care provider-patient relationship: a systematic mapping review of the evidence base Int J Qual Health Care, 25 (6) (2013), pp. 682-688

[16] S. Riva, M. Monti, P. Iannello, G. Pravettoni, P.J. Schulz, A. AntoniettiA preliminary mixed-method investigation of trust and hidden signals in medical consultations PLoS One, 9 (3) (2014), p. e90941

[17] R. Jaeschke, G. Guyatt, D.L. SackettUsers' guides to the medical literature: III. How to use an article about a diagnostic test. A. Are the results of the study valid? Evidence-Based Medicine Working Group JAMA, 271 (5) (1994), pp. 389-391

[18] S.M. WishikThe effective pediatric interview Pediatrics, 21 (1) (1958), pp. 143-147

[19] F.A. Khasawneh, M.A. Slaton, S.L. Katzen, A.A. Woolbert, S.D. Anderson, M.B. Parker, et al.The prevalence and reliability of self-reported penicillin allergy in a community hospital Int J Gen Med, 6 (2013), pp. 905-909

[20] A.M. Kelstrup, P. Juillerat, J. KorzenikThe accuracy of self-reported medical history: a preliminary analysis of the promise of internet-based research in Inflammatory Bowel Diseases J Crohns Colitis, 8 (5) (2014), pp. 349-356

[21] L. Dinc, C. GastmansTrust and trustworthiness in nursing: an argument-based literature review Nurs Inq, 19 (3) (2012), pp. 223-237 
Brand, P.L.P., Dulmen, S. van. Can we trust what parents tell us? A systematic review.

[22] L. Dinc, C. GastmansTrust in nurse-patient relationships: a literature review Nurs Ethics, 20 (5) (2013), pp. 501-516

[23] T. Pelaccia, J. Tardif, E. Triby, C. Ammirati, C. Bertrand, B. Charlin, et al.Do emergency physicians trust their patients? Intern Emerg Med, 11 (4) (2016), pp. 603-608

[24] P. Gulbrandsen, M.L. Clayman, M.C. Beach, P.K. Han, E.F. Boss, E.H. Ofstad, et al.Shared decision-making as an existential journey: Aiming for restored autonomous capacity Patient Educ Couns, 99 (9) (2016), pp. 1505-1510

[25] J.L. BowenEducational strategies to promote clinical diagnostic reasoning N. Engl. J. Med., 355 (21) (2006), pp. 2217-2225

[26] E.J. Emanuel, L.L. EmanuelFour models of the physician-patient relationship JAMA, 267 (16) (1992), pp. 2221-2226

[27] G. Elwyn, A. Lloyd, C. May, T. van der Weijden, A. Stiggelbout, A. Edwards, et al.Collaborative deliberation: a model for patient care Patient. Educ. Couns., 97 (2) (2014), pp. $158-164$

[28] A.M. Stiggelbout, A.H. Pieterse, J.C. De HaesShared decision making: Concepts, evidence, and practice Patient. Educ. Couns., 98 (10) (2015), pp. 1172-1179

[29] J. Bensing, M. Rimondini, A. VisserWhat patients want Patient. Educ. Couns., 90 (3) (2013), pp. 287-290

[30] A.S. DetskyWhat patients really want from health care JAMA, 306 (22) (2011), pp. 25002501

[31] L. RosenbaumThe Paternalism Preference-Choosing Unshared Decision Making N Engl J Med, 373 (7) (2015), pp. 589-592

[32] A. Towle, W. GodolphinFramework for teaching and learning informed shared decision making BMJ, 319 (7212) (1999), pp. 766-771

[33] A.M. Stiggelbout, T.V. Weijden, M.P. Wit, D. Frosch, F. Legare, V.M. Montori, et al.Shared decision making: really putting patients at the centre of healthcare BMJ, 344 (2012), p. e256

[34] J.S. Blumenthal-Barby 'That's the doctor's job': Overcoming patient reluctance to be involved in medical decision making Patient Educ Couns, 100 (1) (2017), pp. 14-17

[35] V.M. Montori, J.P. Brito, M.H. MuradThe optimal practice of evidence-based medicine: incorporating patient preferences in practice guidelines JAMA, 310 (23) (2013), pp. 25032504

[36] C.L. BardesDefining patient-centered medicine N. Engl. J. Med., 366 (9) (2012), pp. 782-783

[37] M.J. Barry, S. Edgman-LevitanShared decision making—pinnacle of patient-centered care N. Engl. J. Med., 366 (9) (2012), pp. 780-781

[38] C. Gore, R.J. Johnson, A.L. Caress, A. Woodcock, A. CustovicThe information needs and preferred roles in treatment decision-making of parents caring for infants with atopic dermatitis: a qualitative study Allergy, 60 (7) (2005), pp. 938-943

[39] B. McKinstryDo patients wish to be involved in decision making in the consultation? A cross sectional survey with video vignettes BMJ, 321 (7265) (2000), pp. 867-871

[40] A. Moreau, L. Carol, M.C. Dedianne, C. Dupraz, C. Perdrix, X. Laine, et al.What perceptions do patients have of decision making (DM)? Toward an integrative patientcentered care model. A qualitative study using focus-group interviews Patient. Educ. Couns., 87 (2012), pp. 206-211

[41] B. Chewning, C.L. Bylund, B. Shah, N.K. Arora, J.A. Gueguen, G. MakoulPatient preferences for shared decisions: a systematic review Patient. Educ. Couns., 86 (1) (2012), pp. 9-18

[42] R. Adams, K. Price, G. Tucker, A.M. Nguyen, D. WilsonThe doctor and the patient-how is a clinical encounter perceived? Patient. Educ Couns., 86 (1) (2012), pp. 127-133

[43] J.M. Bensing, M. Deveugele, F. Moretti, I. Fletcher, L. van Vliet, M. van Bogaert, et al.How to make the medical consultation more succesful from a patient's perspective? Tips for doctors and patients from lay people in the United Kingdom, Italy, Belgium and the Netherlands Patient. Educ. Couns., 84 (2011), pp. 287-293

[44] S. Pollard, N. Bansback, S. BryanPhysician attitudes toward shared decision making: A systematic review Patient Educ Couns, 98 (9) (2015), pp. 1046-1057 
Brand, P.L.P., Dulmen, S. van. Can we trust what parents tell us? A systematic review.

[45] F. Legare, S. Ratte, K. Gravel, I.D. GrahamBarriers and facilitators to implementing shared decision-making in clinical practice: update of a systematic review of health professionals' perceptions Patient. Educ. Couns., 73 (3) (2008), pp. 526-535

[46] C.M. Chan, W.A. AhmadDifferences in physician attitudes towards patient-centredness: across four medical specialties Int J Clin Pract, 66 (1) (2012), pp. 16-20

[47] Y. WitmanWhat do we transfer in case discussions? The hidden curriculum in medicine... Perspect. Med Educ, 3 (2) (2014), pp. 113-123

[48] T. Greenhalgh, J. Howick, N. MaskreyEvidence based medicine: a movement in crisis? BMJ, 348 (2014), p. g3725

[49] P.A. Halvorsen, O.G. Aasland, I.S. KristiansenDecisions on statin therapy by patients' opinions about survival gains: cross sectional survey of general practitioners BMC Fam Pract, 16 (2015), p. 79

[50] M. Kunneman, C.A. Marijnen, T. Rozema, H.M. Ceha, D.A. Grootenboers, K.J. Neelis, et al.Decision consultations on preoperative radiotherapy for rectal cancer: large variation in benefits and harms that are addressed $\mathrm{Br} \mathrm{J}$ Cancer, 112 (1) (2015), pp. 39-43

[51] A.M. Landmark, J. Svennevig, P. GulbrandsenNegotiating treatment preferences: Physicians' formulations of patients' stance Soc Sci Med, 149 (2016), pp. 26-36

[52] E. Wassmer, G. Minnaar, N.A. Aal, M. Atkinson, E. Gupta, S. Yuen, et al. How do paediatricians communicate with children and parents? Acta Paediatr., 93 (11) (2004), pp. 1501-1506

[53] B.L. Sleath, D.M. Carpenter, R. Sayner, G.X. Ayala, D. Williams, S. Davis, et al.Child and Caregiver Involvement and Shared Decision-Making during Asthma Pediatric Visits J. Asthma, 48 (10) (2011), pp. 1022-1031

[54] K.E. Glass, C.E. Wills, C. Holloman, J. Olson, C. Hechmer, C.K. Miller, et al.Shared decision making and other variables as correlates of satisfaction with health care decisi ons in a United States national survey Patient Educ Couns, 88 (1) (2012), pp. 100-105

[55] C. Rathert, M.D. Wyrwich, S.A. BorenPatient-centered care and outcomes: a systematic review of the literature Med Care Res Rev., 70 (4) (2013), pp. 351-379

[56] S.R. Wilson, P. Strub, A.S. Buist, S.B. Knowles, P.W. Lavori, J. Lapidus, et al.Shared treatment decision making improves adherence and outcomes in poorly controlled asthma Am. J. Respir. Crit Care Med., 181 (6) (2010), pp. 566-577

[57] A. Arbuthnott, D. SharpeThe effect of physician-patient collaboration on patient adherence in non-psychiatric medicine Patient. Educ. Couns., 77 (2009), pp. 60-67

[58] R.L. Street Jr., G. Elwyn, R.M. EpsteinPatient preferences and healthcare outcomes: an ecological perspective Expert. Rev. Pharmacoecon. Outcomes. Res., 12 (2) (2012), pp. 167-180

[59] P.L. Brand, T. Klok, A.A. KapteinUsing communication skills to improve adherence in children with chronic disease: The adherence equation Paediatr. Respir. Rev., 14 (4) (2013), pp. 219-223

[60] J.L. Kuntz, M.M. Safford, J.A. Singh, S. Phansalkar, S.P. Slight, Q.L. Her, et al.Patientcentered interventions to improve medication management and adherence: A qualitative review of research findings Patient. Educ. Couns., 97 (2014), pp. 310-326

[61] T. Klok, A.A. Kaptein, E.J. Duiverman, P.L. BrandHigh inhaled corticosteroids adherence in childhood asthma: the role of medication beliefs Eur. Respir. J., 40 (5) (2012), pp. 1149-1155

[62] E.S. Koster, A.H. Wijga, G.H. Koppelman, D.S. Postma, B. Brunekreef, J.C. de Jongste, et al.Uncontrolled asthma at age 8: The importance of parental perception towards medication Pediatr. Allergy Immunol., 22 (5) (2011), pp. 462-468

[63] T. Klok, A.A. Kaptein, P.L. BrandNon-adherence in children with asthma reviewed: The need for improvement of asthma care and medical education Pediatr. Allergy Immunol., 26 (3) (2015), pp. 197-205

[64] T. Klok, A.A. Kaptein, E.J. Duiverman, P.L. BrandLong-term adherence to inhaled corticosteroids in children with asthma: Observational study Respir. Med., 109 (9) (2015), pp. 1114-1119

[65] T. Klok, A.A. Kaptein, E.J. Duiverman, P.L. Brandlt's the adherence, stupid (that determines asthma control in preschool children)! Eur Respir. J., 43 (3) (2014), pp. 783791 
[66] M.E. Rosenbaum, R. AxelsonCurricular disconnects in learning communication skills: what and how students learn about communication during clinical clerkships Patient. Educ. Couns., 91 (1) (2013), pp. 85-90

[67] P.L. Brand, A.M. StiggelboutEffective follow-up consultations: the importance of patientcentered communication and shared decision making Paediatr. Respir. Rev., 14 (4) (2013), pp. 224-228

[68] A. King, R.B. HoppeBest practice for patient-centered communication: a narrative review J Grad Med Educ, 5 (3) (2013), pp. 385-393

[69] M.S. Matthias, M.P. Salyers, R.M. FrankelRe-thinking shared decision-making: Context matters Patient. Educ. Couns., 91 (2) (2013), pp. 176-179

[70] P. Salmon, B. YoungA new paradigm for clinical communication: critical review of literature in cancer care Med Educ (2016)

[71] A.A. Kaptein, T. Klok, R. Moss-Morris, P.L. Brandlllness perceptions: impact on selfmanagement and control in asthma Curr. Opin. Allergy Clin. Immunol., 10 (3) (2010), pp. 194-199

\section{FIGURES AND TABLES}

\section{BOX 1 LEVENTHAL'S SELF-REGULATION THEORY}

Illness representations: the individuals' common-sense definition of health treats - Content:

- Label of the threat (e.g., asthma; cystic fibrosis)

- Symptoms (e.g., shortness of breath, cough)

- Time-line (i.e., time for development of the disease, duration, and recovery)

- Causes (as perceived by the individual)

- Consequences (imagined and real)

- Control (i.e., the degree to which the disease can be cured or controlled) - Organization:

- Feature patterns (i.e., acute, chronic, cyclical)

- Cognitive processing: the way in which individuals experience and value their own symptoms:

○ Strongly influenced by cultural and personal history

- Nourished by experiences from peers

- Evolves over time, e.g. in response to coping procedures

Coping procedures: cognitive and behavioural actions individuals take or do not take to enhance health and to treat and control disease

- Types of coping procedures:

- Wait and see

- Action

- Selection and performance of coping procedure shaped by illness representations, outcome expectations, and perceived risks and benefits of each potential action 
Brand, P.L.P., Dulmen, S. van. Can we trust what parents tell us? A systematic review.

Paediatric Respiratory Reviews: 2017, 24, 65-71

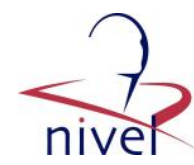

Figure 1. "Common sense" model of self management, adapted from Horne [6].

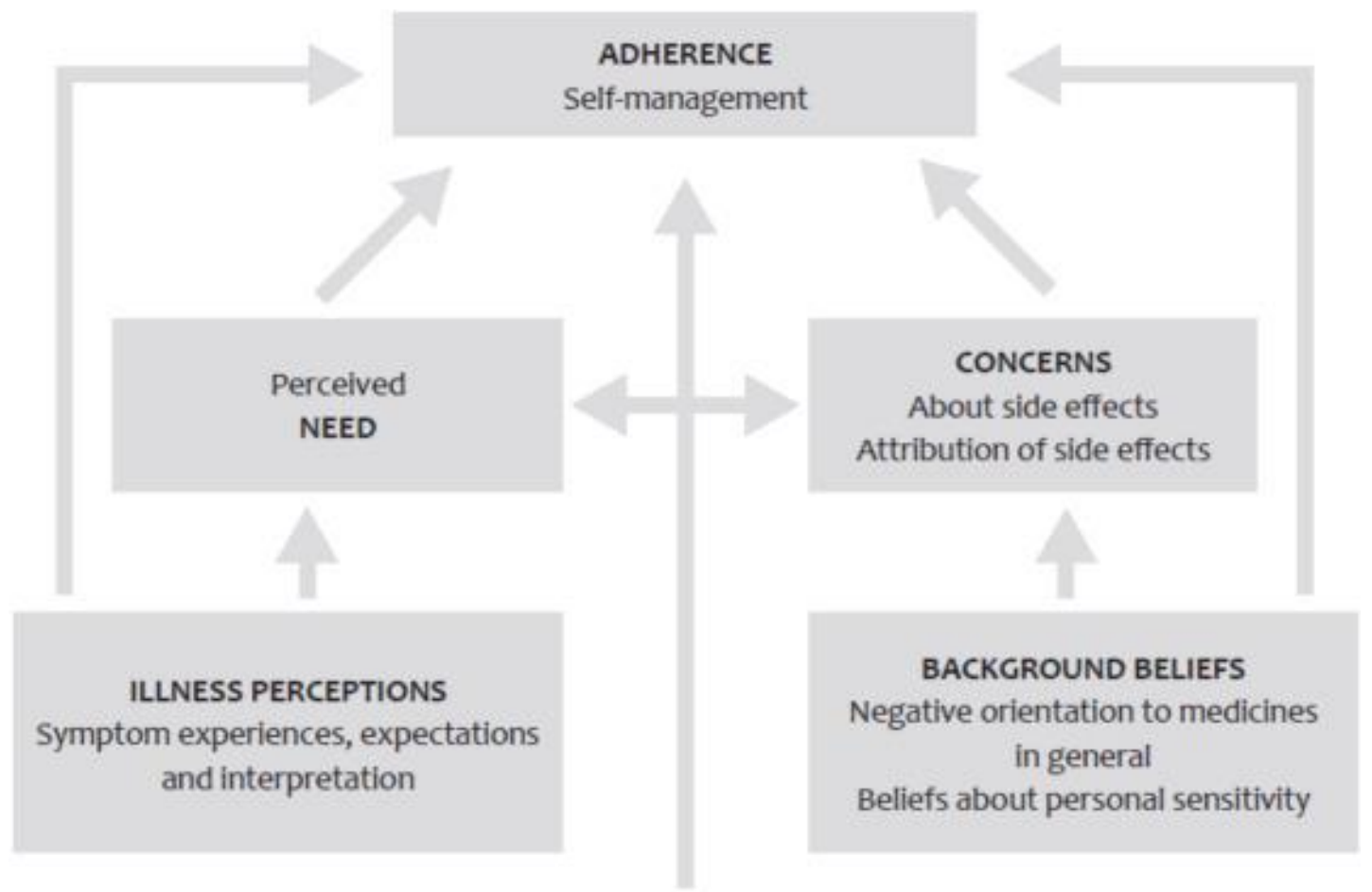

\section{CONTEXTUAL ISSUES}

Past experiences Practical difficulties

Views of others Self-efficacy

Cultural influences Satisfaction 
Brand, P.L.P., Dulmen, S. van. Can we trust what parents tell us? A systematic review.

Table 1. Results of systematic search of literature on "Can we trust what parents tell us?"

\begin{tabular}{|c|c|c|c|c|c|}
\hline $\begin{array}{l}\text { First } \\
\text { author }\end{array}$ & Year & $\begin{array}{r}\text { reference } \\
\text { number }\end{array}$ & Study population & Article description & Main findings \\
\hline Levinson & 1993 & {$[6]$} & $\begin{array}{l}\text { Primary care and hospital- } \\
\text { based physicians }\end{array}$ & $\begin{array}{l}\text { Development of } \\
\text { questionnaire on } \\
\text { "frustrating" } \\
\text { consultations }\end{array}$ & $\begin{array}{l}\text { Lack of trust identified as one of } \\
\text { seven sources of frustration } \\
\text { physicians experience in their } \\
\text { work }\end{array}$ \\
\hline Rogers & 2002 & {$[7]$} & None & $\begin{array}{l}\text { Essay on moral } \\
\text { obligation of } \\
\text { doctors to trust } \\
\text { patients }\end{array}$ & $\begin{array}{l}\text { Trust lays foundation for medical } \\
\text { relationships supporting the } \\
\text { exercise of patient autonomy. } \\
\text { Identifies } 3 \text { barriers of trust: } \\
\text { striving for objectivity of medicine, } \\
\text { social context of medicine, and } \\
\text { manifestation of } \\
\text { dissatisfaction/weariness among } \\
\text { doctors }\end{array}$ \\
\hline Haidet & 2003 & {$[8]$} & None & $\begin{array}{l}\text { Essay on } \\
\text { communication } \\
\text { during history } \\
\text { taking in medicine }\end{array}$ & $\begin{array}{l}\text { Patient and doctor have own } \\
\text { unique perspective on the illness } \\
\text { experience, which influences } \\
\text { information exchange. } \\
\text { Encourages narrative based } \\
\text { medicine }\end{array}$ \\
\hline Gillis & 2005 & {$[9]$} & None & $\begin{array}{l}\text { Review of how } \\
\text { doctors write about } \\
\text { the encounter with } \\
\text { parents in } \\
\text { children's illness }\end{array}$ & $\begin{array}{l}\text { Physicians know they should both } \\
\text { value and distrust the history they } \\
\text { obtain from parents on the child's } \\
\text { health issues }\end{array}$ \\
\hline Street & 2008 & {$[10]$} & Adults in primary care & \begin{tabular}{|l|} 
Cross-sectional \\
study of 214 \\
patients visiting 28 \\
primary care \\
physicians
\end{tabular} & $\begin{array}{l}\text { Patients' perceived similarity with } \\
\text { doctor's beliefs, values, and } \\
\text { communication predicted } \\
\text { patients' trust, satisfaction, and } \\
\text { intent to adhere }\end{array}$ \\
\hline Ammentorp & 2010 & {$[11]$} & $\begin{array}{l}\text { Parents visiting hospital- } \\
\text { based paediatricians }\end{array}$ & $\begin{array}{l}\text { Before-after study of } \\
271 \text { patients of } \\
\text { doctors who had } \\
\text { attended } \\
\text { communication } \\
\text { course }\end{array}$ & $\begin{array}{l}\text { After communication course: } \\
\text { increased patient satisfaction, } \\
\text { particularly on item "the clinician } \\
\text { tried to understand how I } \\
\text { experienced the problem". }\end{array}$ \\
\hline Thom & 2011 & {$[12]$} & HIV +ve adults & $\begin{array}{l}\text { Development and } \\
\text { validation of "trust } \\
\text { in the patient } \\
\text { scale" }\end{array}$ & $\begin{array}{l}\text { 12-item scale with large internal } \\
\text { consistency and significant } \\
\text { construct validity }\end{array}$ \\
\hline Brennan & 2013 & {$[13]$} & $\begin{array}{l}\text { Mostly patients from } \\
\text { primary/oncology/palliative } \\
\text { care }\end{array}$ & $\begin{array}{l}\text { Systematic review } \\
\text { on trust in the } \\
\text { patient-doctor } \\
\text { relationship }\end{array}$ & $\begin{array}{l}<5 \% \text { of } 596 \text { retrieved studies } \\
\text { examined providers' trust in } \\
\text { patients. None of these studies } \\
\text { examined consultations with } \\
\text { children }\end{array}$ \\
\hline Riva & 2014 & {$[14]$} & Adults in primary care & $\begin{array}{l}\text { Cross-sectional } \\
\text { mixed-method } \\
\text { study on } \\
\text { consultations }\end{array}$ & $\begin{array}{l}\text { Patient's trust in physicians } \\
\text { primarily determined by simple } \\
\text { communication signals. } \\
\text { Physician's trust in patients not } \\
\text { examined }\end{array}$ \\
\hline
\end{tabular}


Brand, P.L.P., Dulmen, S. van. Can we trust what parents tell us? A systematic review.

Table 2. principles of patient centred care which may improve the reliability of history data ${ }^{*}$

\begin{tabular}{|l|}
\hline Invest in the beginning: \\
- Collaborative agenda setting \\
- Aligning expectations \\
\hline Elicit the patient's perspective \\
- Illness and medication beliefs \\
- Family and cultural influences \\
- Ideas for next steps \\
\hline Demonstrate empathy \\
- Build and maintain rapport, foster the relationship \\
- Mindful of own thoughts, feelings, distractions, and patient clues \\
- Provide options, share pros and cons \\
- Acknowledge cues with empathic responses \\
\hline Invest in the end \\
- Cocreate a plan, incorporating patient preferences \\
- Invite patient to ask questions \\
- Allow time to adjust plan in response to patient preferences \\
\hline
\end{tabular}

adapted from $[7,60,65,66]$

\section{APPENDIX 1}

\section{Appendix 1: literature search strategy}

We searched PubMed, Embase and Psycinfo using the following search terms:

\section{Parents}

"Parents"[Mesh] OR parent*[tiab] OR "Parenthood Status"[tiab] OR “Step-

Parent*"[tiab] OR “Step Parent*”[tiab] OR Stepparent*[tiab] OR Family*[tiab] OR

"Family Member*"[tiab] OR Stepfamil*[tiab] OR "Reconstituted Famil*"[tiab] OR

Relative*[tiab] OR "Extended Famil*"[tiab] OR "Family"[Mesh] OR

"Parenting"[Mesh] OR "Single-Parent Family"[Mesh] OR "Single Parent

Famil*"[tiab] OR "One-Parent Famil*"[tiab] OR "Single Parent"[Mesh] OR "Single

Parent*"[tiab] OR "Single Stepparent*"[tiab] OR "Single Step-Parent*"[tiab] OR

"Parent-Child Relations"[Mesh] OR "Parent Child Relation*”[tiab] OR "Parent-

Child Relationship*"[tiab] OR "natural parent*"[tiab] OR "adoptive parent*"[tiab]

OR "substitute parent*"[tiab] OR parenthood[tiab]

\section{History}

"Medical History Taking"[Mesh] OR "Medical History Taking"[tiab] OR anamnesis[tiab] OR "history taking”[tiab] OR "Diagnosis"[Mesh] OR "Diagnosis"[tiab] OR "Diagnoses"[tiab] OR “diagnostic bias”[tiab]

\section{Trust}

Reliability[tiab] OR trust[tiab] OR "Trust"[Mesh] OR Confidence[tiab] OR reliance[tiab] OR "Truth Disclosure"[Mesh] OR "Truth Disclosure"[tiab] OR "Information Disclosure"[tiab] OR "Revealing of information"[tiab] OR misinformation[tiab] OR exaggerate[tiab] OR overstatement[tiab] OR "magnify problem*”[tiab] OR "Denial (Psychology)"[Mesh] OR denial[tiab] OR deny[tiab] 
OR “qualify a statement”[tiab] OR ignorance[tiab] OR misinterpretation*[tiab] OR "Fear"[Mesh] OR fear[tiab] OR concerned[tiab] OR worried[tiab] OR worry[tiab] OR “concern about”[tiab] OR “concern for"[tiab] OR “out of concern”[tiab] OR distrust[tiab] OR mistrust[tiab]

\section{Communication about symptoms and signs}

"somatic complaint*"[tiab] OR presentation[tiab] OR "presents with complaint*" OR symptom*[tiab] OR manifestation*[tiab]

\section{Parents' perspective}

"parent perspective*" OR "parental perspective*" OR "parental perception*” OR "parental attribution*" OR "maternal perception*" OR "inaccurate perception*" OR "parent awareness" OR "illness representation" OR "illness perception*"

\section{Children}

PM: child*[tw] OR schoolchild*[tw] OR infan*[tw] OR adolescen*[tw] OR pediatri*[tw] OR paediatr*[tw] OR neonat*[tw] OR boy[tw] OR boys[tw] OR boyhood[tw] OR girl[tw] OR girls[tw] OR girlhood[tw] OR youth[tw] OR youths[tw] OR baby[tw] OR babies[tw] OR toddler*[tw] OR "Mental Disorders Diagnosed in Childhood"[MeSH] OR teen[tw] OR teens[tw] OR teenager*[tw] OR newborn*[tw] OR postneonat*[tw] OR postnat*[tw] OR perinat*[tw] OR puberty[tw] OR preschool*[tw] OR suckling*[tw] OR picu[tw] OR nicu[tw] PM extensive complete 0-18 years old (Mol): infan*[tw] OR child*[tw] OR adolescen*[tw] OR pediatric*[tw] OR paediatric*[tw] OR pube*[tw] OR juvenil*[tw] OR school*[tw] OR newborn*[tiab] OR new-born*[tiab] OR neonat*[tiab] OR neonat*[tiab] OR premature*[tiab] OR postmature*[tiab] OR premature*[tiab] OR post-mature*[tiab] OR preterm*[tiab] OR pre-term*[tiab] OR baby[tiab] OR babies[tiab] OR toddler*[tiab] OR youngster*[tiab] OR preschool*[tiab] OR kindergart*[tiab] OR kid[tiab] OR kids[tiab] OR playgroup*[tiab] OR play-group*[tiab] OR playschool*[tiab] OR prepube*[tiab] OR preadolescen*[tiab] OR junior high*[tiab] OR highschool*[tiab] OR senior high[tiab] OR young people*[tiab] OR minors[tiab] NOT (animals[mh] NOT (humans[mh] AND animals[mh]))

PM extensive complete (Leclercq): infan* OR newborn* OR new-born* OR perinat* OR neonat* OR baby OR baby* OR babies OR toddler* OR minors OR minors* OR boy OR boys OR boyfriend OR boyhood OR girl* OR kid OR kids OR child OR child* OR children* OR schoolchild* OR schoolchild OR school child[tiab] OR school child*[tiab] OR adolescen* OR juvenil* OR youth* OR teen* OR under*age* OR pubescen* OR pediatrics[mh] OR pediatric* OR paediatric* OR peadiatric* OR school[tiab] OR school*[tiab] OR prematur* OR preterm* 
Brand, P.L.P., Dulmen, S. van. Can we trust what parents tell us? A systematic review.

\section{Medical communication}

PubMed: "Interpersonal Relations"[Mesh] OR “interpersonal relation*”[tiab] OR "interpersonal communication" OR "Social Interaction*”[tiab] OR "human relation"[tiab] OR "Physician-Patient Relations"[Mesh] OR "Physician Patient Relation*"[tiab] OR "Physician Patient Relationship*"[tiab] OR "Doctor Patient Relation*"[tiab] OR "Nurse-Patient Relations"[Mesh] OR "Nurse Patient Relation*"[tiab] OR "Nurse Patient Relationship*"[tiab] OR "Health Communication"[Mesh] OR "Health Communication*"[tiab] OR "Communication"[Mesh] OR communication[tiab] OR "Personal Communication" [tiab] OR Misinformation[tiab] OR "Communication Program*"[tiab] OR "Professional-Patient Relations"[Mesh] OR "Professional Patient Relation*"[tiab] OR "Professional Patient Relationship*"[tiab] OR "Contacting Client*"[tiab] OR "Health Personnel"[Mesh] OR "Health Care Provider*"[tiab]

Psycinfo: DE "Interpersonal Relationships" OR DE "Interpersonal Interaction" OR DE "Interpersonal Communication" OR DE "Communication Barriers" OR DE "Social Interaction" OR TI interpersonal W0 relation* OR AB interpersonal W0 relation* OR TI Interpersonal W0 Communication OR AB Interpersonal W0 Communication OR TI Social W0 Interaction* OR AB Social W0 Interaction* OR TI human W0 relation* OR AB human W0 relation* OR TI Physician W1 Patient W0 Relation* OR AB Physician W1 Patient W0 Relation* OR TI Doctor W1 Patient W0 Relation* OR AB Doctor W1 Patient W0 Relation* OR TI Nurse W1 Patient W0 Relation* OR AB Nurse W1 Patient W0 Relation* OR DE "Communication Skills" OR TI Health W0 Communication* OR AB Health W0 Communication* OR DE "Communication" OR TI communication OR AB communication OR TI Personal W0 Communication OR Personal W0 Communication OR TI Misinformation OR AB Misinformation OR TI Communication W0 Program* OR AB Communication W0 Program* OR TI Professional W1 Patient W0 Relation* OR AB Professional W1 Patient W0 Relation* OR TI Contacting W0 Client OR AB Contacting W0 Client OR DE "Health Personnel" OR TI Health W0 Personnel OR AB Health W0 Personnel OR TI Health W0 Care W0 Provider* OR AB Health W0 Care W0 Provider*

Search terms were then combined as follows:

\begin{tabular}{|c|c|c|c|c|}
\hline \#69 & $\underline{\text { Add }}$ & Search \#68 AND \#54 & $\underline{150}$ & $10: 19: 15$ \\
\hline \#68 & $\underline{\text { Add }}$ & $\begin{array}{l}\text { Search "parent perspective*" OR "parental } \\
\text { perspective*" OR "parental perception*" OR } \\
\text { "parental attribution*" OR "maternal } \\
\text { perception" OR "inaccurate perception*" OR } \\
\text { "parent awareness" OR "illness representation" }\end{array}$ & $\underline{982}$ & 10:18:44 \\
\hline & $\underline{\text { Add }}$ & Search parents perception symptoms & $\underline{2863}$ & $10: 05: 24$ \\
\hline & $\underline{\text { Add }}$ & Search parents perception & $\underline{7213}$ & $10: 05: 10$ \\
\hline & $\underline{\text { Add }}$ & Search parents presenting history & $\underline{345}$ & 10:04:53 \\
\hline & $\underline{\text { Add }}$ & Search parents presenting symptoms to physicians & $\underline{98}$ & $10: 04: 26$ \\
\hline
\end{tabular}




\begin{tabular}{|c|c|c|c|c|}
\hline \#60 & $\underline{\text { Add }}$ & Search parents presenting symptoms & $\underline{1433}$ & 10:03:59 \\
\hline$\# 58$ & $\underline{\text { Add }}$ & Search \#56 AND \#40 & $\underline{492}$ & 10:01:42 \\
\hline \#56 & $\underline{\text { Add }}$ & Search \#55 AND \#43 & $\underline{3790}$ & 09:59:11 \\
\hline \#55 & $\underline{\text { Add }}$ & Search \#41 AND \#54 & $\underline{66580}$ & $09: 58: 25$ \\
\hline \#54 & $\underline{\text { Add }}$ & $\begin{array}{l}\text { Search "somatic complaint*"[tiab] OR } \\
\text { presentation[tiab] OR "presents with } \\
\text { complaint*" OR symptom*[tiab] OR } \\
\text { manifestation*[tiab] }\end{array}$ & $\underline{1215275}$ & $09: 57: 30$ \\
\hline \#46 & $\underline{\text { Add }}$ & Search \#44 AND \#45 & $\underline{1799}$ & $09: 27: 17$ \\
\hline \#45 & $\underline{\text { Add }}$ & $\begin{array}{l}\text { Search child*[tw] OR schoolchild*[tw] OR } \\
\text { infan*[tw] OR adolescen*[tw] OR pediatri*[tw] } \\
\text { OR paediatr*[tw] OR neonat*[tw] OR boy[tw] } \\
\text { OR boys[tw] OR boyhood[tw] OR girl[tw] OR } \\
\text { girls[tw] OR girlhood[tw] OR youth[tw] OR } \\
\text { youths[tw] OR baby[tw] OR babies[tw] OR } \\
\text { toddler*[tw] OR "Mental Disorders Diagnosed in } \\
\text { Childhood"[MeSH] OR teen[tw] OR teens[tw] } \\
\text { OR teenager*[tw] OR newborn*[tw] OR } \\
\text { postneonat*[tw] OR postnat*[tw] OR } \\
\text { perinat*[tw] OR puberty[tw] OR preschool*[tw] } \\
\text { OR suckling*[tw] OR picu[tw] OR nicu[tw] }\end{array}$ & 3676246 & $09: 26: 05$ \\
\hline \#44 & $\underline{\text { Add }}$ & Search \#42 AND \#43 & $\underline{3998}$ & 09:18:06 \\
\hline \#43 & $\underline{\text { Add }}$ & $\begin{array}{l}\text { Search "Interpersonal Relations"[Mesh] OR } \\
\text { "interpersonal relation*"[tiab] OR "interpersonal } \\
\text { communication" OR "Social Interaction*"[tiab] } \\
\text { OR "human relation"[tiab] OR "Physician- } \\
\text { Patient Relations"[Mesh] OR "Physician Patient } \\
\text { Relation*"[tiab] OR "Physician Patient } \\
\text { Relationship*"[tiab] OR "Doctor Patient } \\
\text { Relation*"[tiab] OR "Nurse-Patient } \\
\text { Relations"[Mesh] OR "Nurse Patient } \\
\text { Relation*"[tiab] OR "Nurse Patient } \\
\text { Relationship*"[tiab] OR "Health } \\
\text { Communication"[Mesh] OR "Health } \\
\text { Communication*"[tiab] OR } \\
\text { "Communication""[Mesh] OR } \\
\text { communication[tiab] OR "Personal } \\
\text { Communication"[tiab] OR Misinformation[tiab] } \\
\text { OR "Communication Program*"[tiab] OR } \\
\text { "Professional-Patient Relations"[Mesh] OR } \\
\text { "Professional Patient Relation*"[tiab] OR } \\
\text { "Professional Patient Relationship*"[tiab] OR } \\
\text { "Contacting Client*"[tiab] OR "Health }\end{array}$ & $\underline{1068544}$ & 09:17:44 \\
\hline
\end{tabular}




\begin{tabular}{|c|c|c|c|c|}
\hline & & $\begin{array}{l}\text { Personnel"[Mesh] OR "Health Care } \\
\text { Provider*"[tiab] }\end{array}$ & & \\
\hline$\# 42$ & $\underline{\text { Add }}$ & Search \#41 AND \#40 & $\underline{40895}$ & 09:17:00 \\
\hline$\# 41$ & $\underline{\text { Add }}$ & Search \#38 AND \#39 & $\underline{585411}$ & 09:16:10 \\
\hline \#40 & $\underline{\text { Add }}$ & $\begin{array}{l}\text { Search Reliability[tiab] OR trust[tiab] OR } \\
\text { "Trust"[Mesh] OR Confidence[tiab] OR } \\
\text { reliance[tiab] OR "Truth Disclosure"[Mesh] OR } \\
\text { "Truth Disclosure"[tiab] OR "Information } \\
\text { Disclosure"[tiab] OR "Revealing of } \\
\text { information"[tiab] OR misinformation[tiab] OR } \\
\text { exaggerate[tiab] OR overstatement[tiab] OR } \\
\text { "magnify problem""[tiab] OR "Denial } \\
\text { (Psychology)"[Mesh] OR denial[tiab] OR } \\
\text { deny[tiab] OR “qualify a statement"[tiab] OR } \\
\text { ignorance[tiab] OR misinterpretation*[tiab] OR } \\
\text { "Fear"[Mesh] OR fear[tiab] OR concerned[tiab] } \\
\text { OR worried[tiab] OR worry[tiab] OR “concern } \\
\text { about"[tiab] OR "concern for"[tiab] OR “out of } \\
\text { concern"[tiab] }\end{array}$ & $\underline{612850}$ & 09:15:49 \\
\hline \#39 & $\underline{\text { Add }}$ & $\begin{array}{l}\text { Search "Medical History Taking"[Mesh] OR } \\
\text { "Medical History Taking"[tiab] OR } \\
\text { anamnesis[tiab] OR "history taking"[tiab] OR } \\
\text { "Diagnosis"[Mesh] OR "Diagnosis"[tiab] OR } \\
\text { "Diagnoses"[tiab] }\end{array}$ & $\underline{7528950}$ & 09:15:31 \\
\hline \#38 & $\underline{\text { Add }}$ & 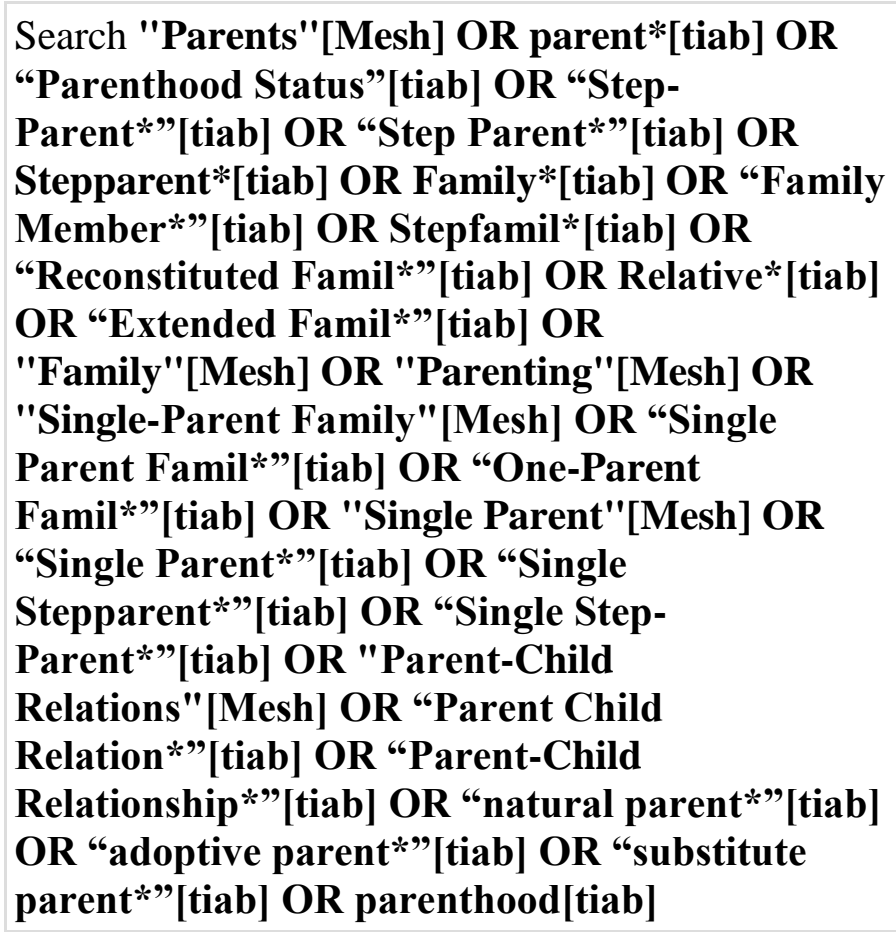 & 2056701 & 09:15:00 \\
\hline$\underline{\# 0}$ & $\underline{\text { Add }}$ & pubmed clipboard & $\underline{3}$ & $10: 20: 56$ \\
\hline
\end{tabular}


Brand, P.L.P., Dulmen, S. van. Can we trust what parents tell us? A systematic review.

Paediatric Respiratory Reviews: 2017, 24, 65-71 